\title{
Comparison of Prostaglandin E1 and Sildenafil Citrate Administration on Skin Flap Survival in Rats
}

\author{
Ji-An Choi, \\ Keun-Cheol Lee, \\ Min-Su Kim, \\ Seok-Kwun Kim \\ Department of Plastic and Reconstructive \\ Surgery, Dong-A University School of \\ Medicine, Busan, Korea
}

\begin{abstract}
Background: Alprostadil and sildenafil are known vasodilators used independently to improve flap survival in animal models. In this study, we investigate whether these agents act synergistically to decrease flap necrosis in rat models.

Methods: After acclimation period, 4 groups of 10 male white rats were given a modified McFarlane skin flap. The postoperative treatment included saline control (Group A), sildenafil citrate-only (Group B), alprostadil-only (Group C), and both sildenafil and alprostadil (Group D). The flaps were observed on postoperative days 1, 3, 5 and 7 . The animals were euthenized on postoperative day 7 , and the flaps were evaluated for inflammation and neovascularization.

Results: At each observation, the mean necrotic index was significantly lower for all three treatment groups (Groups A, B, C) and was the lowest for the combined treatment group. On histologic evaluations, combined treatment was associated with decreased inflammation and increased capillary vessel formation, when compared with control group. Conclusion: Both sildenafil-only and alprostadil treatments were independently associated with increased flap survival rate. Sildenafil citrate and alprostadil had a synergistic effect in increasing flap survival rate.
\end{abstract}

Keywords: Alprostadil / Sildenafil / Rats, Sprague-Dawley / Surgical flaps / Survival rate
No potential conflict of interest relevant to this article was reported.

\section{INTRODUCTION}

Flap necrosis is a physiologic consequence of prolonged ischemia in a surgical flap. Regardless of causes, partial or whole flap necrosis is regarded as a major complication and such events can result in wound dehiscence, infection, delayed healing, and fistula formation. These complications often prolong postoperative hospitalization and may require additional surgical management with less-than-optimal outcomes.

\footnotetext{
Correspondence: Keun-Cheol Lee

Department of Plastic and Reconstructive Surgery, Dong-A University School of Medicine, 26 Daesingongwon-ro, Seo-gu, Busan 49201, Korea

E-mail: pokdungi@dau.ac.kr

*This study was supported by the research funds of Dong-A University

*This study is a master's thesis from 2015 Graduate school of Dong-A University

School of Medicine.
}

Received June 19, 2015 / Revised July 22, 2015 / Accepted August 5, 2015
The most important aspect of flap survival following a graft event is the continued delivery of oxygen and nutrients to the flap tissue. For this purpose, efforts are made to select flap containing a definite pedicle, to implement various preoperative surgical delay procedures, and to administer various medicines in the early postoperative period. Additional methods of increasing oxygen delivery to the flap includes hyperbaric oxygenation therapy. Postoperative surveilance is crucial for identifying and management vascular events earlier on, before the irreversible ischemic changes occur in the flap tissue [1].

Prostaglandin E1 (PGE1) is a well-known vasodilatory eicosanoid and is used to treat occlusive vascular diseases and enhance the flap survival rate. Sildenafil citrate is another vasodilatory agent. This phosphodiesterase inhibitor was originally developed for the treatment of angina but was later found to be effective 
in treating erectile dysfunction.

This animal study was designed to compare flap survivability between sildenafil citrate and PGEl and to evaluate whether these effects are synergistic between the two agents.

\section{METHODS}

\section{Flap creation and postoperative management of rats}

Upon approved from the institutional animal experimentation ethics review committee, Sprague-Dawley rats were obtained $(\mathrm{n}=40)$. The rats were 12 weeks old, weighed between 300 to $400 \mathrm{~g}$, and given a week of adaptation with ad lib water and feed.

On the day of operation, each rat was intramuscularly injected with $0.1 \mathrm{~mL} / 100 \mathrm{~g}$ of tiletamine and zolazepam mixture (Virbac Korea Co., Seoul, Korea). Once under full anesthesia, the back was prepared with an electric shaver, and the dorsal surgical site was treated with povidone and alcohol. A modified $2 \times 8 \mathrm{~cm}$ McFarlane skin flap was designed over the dorsum between the neck and iliac crest. The flap area was injected with $2 \%$ lidocaine without epinephrine. The skin was incised with a No. $15 \mathrm{knife}$, and the flap was elevated along the plane just deep to the panniculus carnosus. The flap was then sutured back into the original position using 4-0 nylon. Cefazedone sodium (Pazeron, Hanlim Pharm. Co., Seoul, Korea) was intramuscularly injected for three days postoperatively $(5 \mathrm{mg} / \mathrm{kg} / \mathrm{day})$.

The rats were randomly assigned into four groups of 10 animals each. Group A served as control and was administered with oral an intravenous saline solution. Group B was administered with oral saline solution and intravenous alprostadil (Eglandin, Mitsubishi Tanabe Pharma Co., Ltd., Seoul, Korea). Group C was administered with oral sildenafil citrate (Viagra, Pfizer Australia Pty Ltd., West Ryde, Australia) and intravenous saline solution. Group D was administered with oral sildenafil citrate and intravenous alprostadil.

For Groups C and D, oral sildenafil table (100 mg/tab) was ground with pestle and mortar, dissolved in $10 \mathrm{~mL}$ saline solution, and fed through a flexible gastric tube $(20 \mathrm{mg} / \mathrm{kg} / \mathrm{day})$ for 7 days. For Groups B and D, alprostadil (10 $\mu \mathrm{g} / 2 \mathrm{~mL}$ ampoule) was diluted to a concentration of $1 \mu \mathrm{g} / \mathrm{mL}$. After warming up the tail with infrared lamp to $30^{\circ} \mathrm{C}-35^{\circ} \mathrm{C}$, the solution was injected into the dilated vein through a 24 -gauge needle $(1 \mu \mathrm{g} / \mathrm{kg} /$ day) for 7 days

\section{Photographic flap necrosis evaluation}

The flaps were photographed on postoperative days $1,3,5$, and 7 . The photographs were loaded into Image J software (National Institute of Health) and evaluated by three observers who were blinded to the treatment regimen. Each flap was evaluated for the extent of necrosis as a percentage of total flap area (necrotic index, $\mathrm{NI}$. The values were averaged between the observers and compared across the observations (Fig. 1).

\section{Tissue specimen preparation and histological observation}

In each group, a randomly selected animal was sacrificed on postoperative days 1, 3, and 5 for histologic evaluation. All of the remaining rats were euthenized on postoperative day 7 . The flaps were harvested and fixed in a 10\% neutral formalin solution for two days. After paraffin fixation, 2-cm sections were stained with H\&E stain. The specimens were examined at 10, 20, and 200 magnifications and were evaluated for epidermal exfoliation due to necrosis, acute and chronic inflammation, granulation tissue formation, and fibrosis. Also, neovascularization was quantified by the number of new capillaries present within a $200 \times$ field

\section{Statistical analysis}

The SPSS ver. 22.0 package was used for statistical analysis of the NI. Results were expressed in means and standard deviations. The values were compared across the four groups using one-way analysis of variance (ANOVA). Post-hoc analyses were used for multicomparison through the least significance difference method. Statistical significance was accepted for $p<0.05$. 


\section{RESULTS}

\section{Photographic evaluation}

All of the animals survived through the study duration, except for those sacrificed for early histologic evaluation. The mean final necrotic areas were 795.1, 558.8, 644.4, and $417.6 \mathrm{~mm}^{2}$ for Groups A to $\mathrm{D}$, respectively, and these represented $56 \%, 42 \%, 45 \%, 31 \%$ of the total respective flap areas (Table 1, Figs. 1, 2).

To investigate initial pace of necrosis, we compared the extent of necrosis in each group on days $1,3,5$, and 7 to the final necrotic dimension. On postoperative day 1 , the mean necrotic areas were $444.0 \mathrm{~mm}^{2}(\mathrm{NI}=31.8 \%), 268.3 \mathrm{~mm}^{2}(\mathrm{NI}=20.0 \%), 326.4 \mathrm{~mm}^{2}$ $(\mathrm{NI}=24.4 \%)$, and $223.8 \mathrm{~mm}^{2}(\mathrm{NI}=17.1 \%)$ for Groups A to D. On postoperative day 3 , the mean necrotic areas were $579.5 \mathrm{~mm}^{2}$ $(\mathrm{NI}=41.3 \%), 366.1 \mathrm{~mm}^{2}(\mathrm{NI}=26.8 \%), 519.5 \mathrm{~mm}^{2}(\mathrm{NI}=33.1 \%)$, and $326.4 \mathrm{~mm}^{2}(\mathrm{NI}=23.7 \%)$. On postoperative day 5 , the mean necrotic areas were $717.4 \mathrm{~mm}^{2}(\mathrm{NI}=51.0 \%), 439.8 \mathrm{~mm}^{2}(\mathrm{NI}=32.7 \%), 550.2$

Table 1. Comparison of flap viability

\begin{tabular}{ccccc|} 
Group & $\begin{array}{c}\text { Minimum } \\
\text { necrotic area } \\
\left(\mathrm{mm}^{2}\right)\end{array}$ & $\begin{array}{c}\text { Maximum } \\
\text { necrotic area } \\
\left(\mathrm{mm}^{2}\right)\end{array}$ & $\begin{array}{c}\text { Mean } \\
\text { necrotic area } \\
\left(\mathrm{mm}^{2}\right)\end{array}$ & $\begin{array}{c}\text { Mean } \\
\text { necrosis rate } \\
(\mathrm{ni})(\%)\end{array}$ \\
\hline Day 1 & & & & \\
\hline A & 330.7 & 513.5 & 444.0 & 31.8 \\
\hline B & 18.4 & 468.8 & 268.3 & 20.0 \\
\hline C & 179.1 & 456.6 & 326.4 & 24.4 \\
\hline D & 56.4 & 437.4 & 223.8 & 17.1 \\
\hline Day 3 & & & & \\
\hline A & 378.0 & 657.8 & 579.5 & 41.3 \\
\hline B & 210.0 & 501.2 & 366.1 & 26.8 \\
\hline C & 330.0 & 681.6 & 519.5 & 33.1 \\
\hline D & 75.0 & 547.8 & 326.4 & 23.7 \\
\hline Day 5 & & & & \\
\hline A & 455.9 & 904.1 & 717.4 & 51.0 \\
\hline B & 258.2 & 702.9 & 439.8 & 32.7 \\
\hline C & 476.4 & 684.2 & 550.2 & 39.2 \\
\hline D & 138.3 & 646.9 & 399.3 & 29.2 \\
\hline Day 7 & & & & \\
\hline A & 316.1 & 975.5 & 795.1 & 56.8 \\
\hline B & 368.4 & 850.8 & 558.5 & 42.0 \\
\hline C & 474.6 & 798.0 & 644.4 & 45.3 \\
\hline D & 141.1 & 715.5 & 417.6 & 31.0 \\
\hline & & & & \\
\hline
\end{tabular}

$\mathrm{mm}^{2}(\mathrm{NI}=39.2 \%)$, and $399.3 \mathrm{~mm}^{2}(\mathrm{NI}=29.2 \%)$. On postoperative day 7 , the mean necrotic areas were $795.1 \mathrm{~mm}^{2}(\mathrm{NI}=56.8 \%), 558.5 \mathrm{~mm}^{2}$ $(\mathrm{NI}=42.0 \%), 644.4 \mathrm{~mm}^{2}(\mathrm{NI}=45.3 \%)$, and $417.6 \mathrm{~mm}^{2}(\mathrm{NI}=31.0 \%)$.

Overall, the control group of rats showed the highest average areas of flap necrosis at each evaluation. There were no significant patterns in maximum and minimum necrosis areas with respect to the administration of sildenafil or alprostadil (Table 1).

\section{Histological findings}

Epidermal exfoliation and flap detachment was greater in the
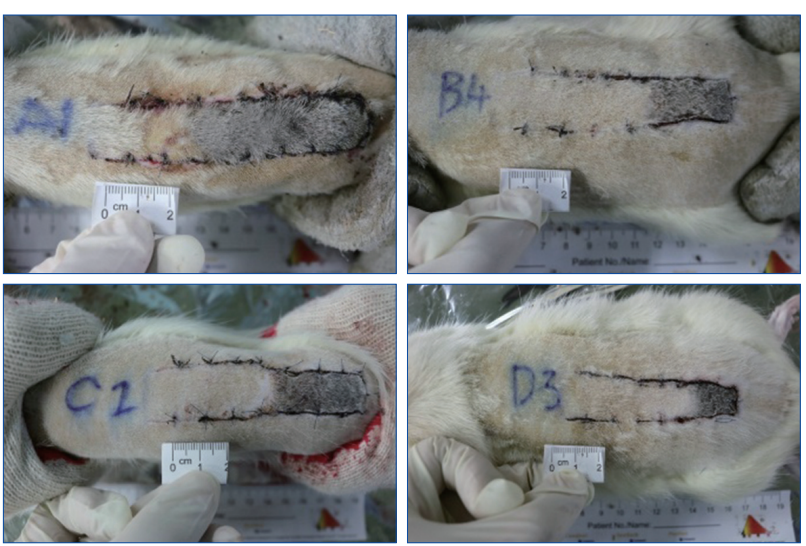

Fig. 1. Comparison of flap viability on postoperative day 7 . Throughout the entire study duration, flap necrosis was the highest in the control group (Group A).

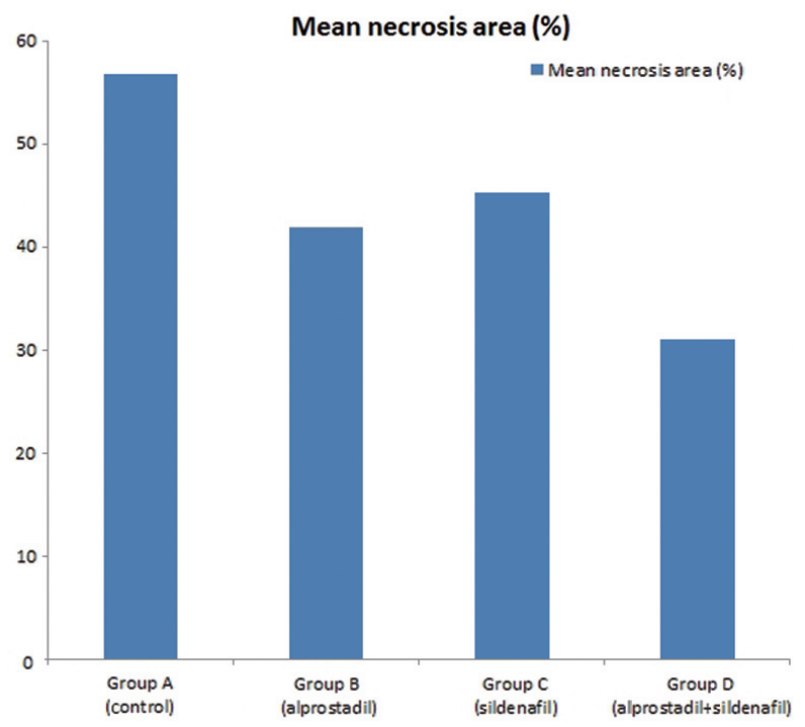

Fig. 2. Mean necrosis area on postoperative day 7 in each group. 
control group of rats (Group A) than in any other group. This group of rats demonstrated the greatest extent of neutrophil infiltration, inflammation, and hypodermic fibrosis.

In Group B, epidermal exfoliation was less than in Group A but greater than Group D. Flaps from Group B rats was found to have moderate neutrophil infiltration. This group had less fibrosis, more granulation tissue formation, and higher density of new capillary formation than Group A.

In Group C, epidermal exfoliation was less than in Group A and greater than in Group D. While more favorable than in Group A, the neutrophilic infiltration and inflammatory responses in this alprostadil-only group were more intense in this group when compared to sildenafil-only or sildenafil-and-alprostadil groups (B and $\mathrm{D})$.
In Group D, epidermal exfoliation was less than in any other groups. The co-administration of sildenafil and alprostadil was associated with relatively lower levels of neutrophilic and lymphocytic infiltration. The highest desnity of capillary vessel formation was observed in this group (Table 2, Fig. 3).

Table 2. Relative degree of histological findings in each group

\begin{tabular}{|c|c|c|c|c|c|c|}
\hline Group & $\begin{array}{l}\text { Neutrophil } \\
\text { infiltration } \\
\text { (acute } \\
\text { inflammation) }\end{array}$ & $\begin{array}{l}\text { Lymphocyte } \\
\text { infiltration } \\
\text { (chronic } \\
\text { inflammation) }\end{array}$ & Fibr & Necr & $\begin{array}{c}\text { s Granulation } \\
\text { tissue }\end{array}$ & $\begin{array}{c}\text { New } \\
\text { capillary } \\
\text { blood vesse } \\
\text { (count) }\end{array}$ \\
\hline A & ++ & ++ & ++ & +++ & ++ & $+(0-4)$ \\
\hline B & + & ++ & ++ & + & ++ & $+++(18-22)$ \\
\hline C & ++ & ++ & ++ & ++ & + & $++(12-16)$ \\
\hline D & + & ++ & ++ & + & ++ & $+++(31-38)$ \\
\hline
\end{tabular}

The degree of lymphocyte infiltration and fibrosis in each group showed no significant differences.

+ , few; ++, moderately; +++: much.
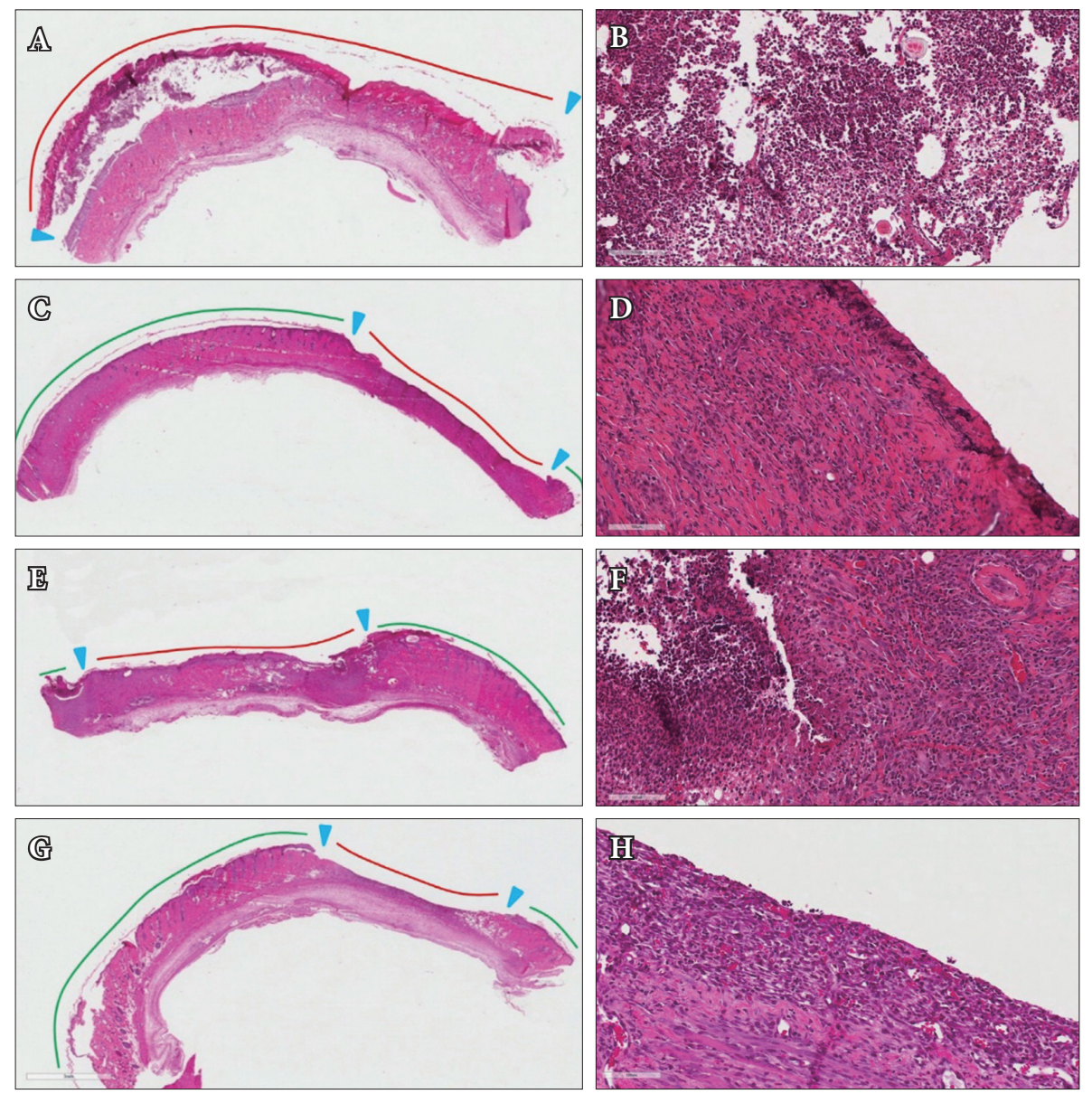

Fig. 3. Histologic appearance on postoperative day 7. Control group (H\&E): (A) $\times 10$, (B) $\times 200$. Alprostadil-only group $(H \& E)$ : (C) $\times 10$ (D) $\times 200$. Sildenafil-only group $(H \& E)$ : $(E) \times 10,(F) \times 200$. Alprostadil and Sildenafil group $(H \& E):(G) \times 10,(H) \times 200$. Red line, skin detachment area; green line, skin maintenance area. 


\section{Statistical analysis of flap necrosis area}

The mean NI was compared across the four groups using one-way ANOVA. The mean flap necrosis area rate was lowest in combined treatment (Group D, 31.0\%) and was highest in control animals (Group A, 56.7\%) throughout the experiment ( $p$-value $<0.05)$. Comparing single-agent treatments, the mean NI was higher for alprostadil-only administration (Group C) than for sildenafil-only administration (Group B), though this was not statistically significant. Aprostadil-only administration was associated with significantly higher mean NI, compared to combined treatment ( $p$-value $<0.05)$. Sildenafil-only administration was also associated with higher mean NI compared to combined treatment, though this was not statistically significant observation (Table 3).

\section{DISCUSSION}

Skin flaps are used widely in the reconstruction of surface defects in various parts of the body. Regardless of flap classification, all flaps require a minimal amount of oxygen and nutrient delivery in the initial period of grafting, which is dependent on adequate blood flow [2]. Tissue necrosis is not an uncommon complication following flap reconstruction. This is almost always due to insufficient blood flow (whether from insufficient arterial supply or from increased hydrostatic pressure secondary to venous congestion).

However, flap ischemia and necrosis are influenced by a complex set of pathophysiological events. Both local and systemic factors are associated with nutrition and oxygen delivery to flap tissue, precursor metabolites and markers of necrosis, and with

Table 3. Statistical analysis of necrotic index (one-way analysis of variance test)

\begin{tabular}{llllll} 
& Group A & Group B & Group C & Group D & $p$-value \\
\hline Day 1 & $31.8 \pm 3.7$ & $20.0 \pm 8.9$ & $24.4 \pm 6.6$ & $17.1 \pm 10.4$ & 0.001 \\
Day 3 & $41.3 \pm 7.7$ & $26.8 \pm 8.2$ & $33.1 \pm 8.1$ & $23.7 \pm 11.2$ & $<0.001$ \\
\hline Day 5 & $51.0 \pm 9.1$ & $32.7 \pm 10.8$ & $39.2 \pm 5.0$ & $29.2 \pm 13.8$ & $<0.001$ \\
Day 7 & $56.8 \pm 15.6$ & $42.0 \pm 11.2$ & $45.3 \pm 6.6$ & $31.0 \pm 14.1$ & $<0.001$ \\
\hline
\end{tabular}

Values are presented as means.

Group A ( $\mathrm{n}=10)$, saline (control group); Group B ( $\mathrm{n}=10)$, alprostadil; Group C $(\mathrm{n}=10)$, sildenafil; Group D ( $\mathrm{n}=10)$, alprostadil and sildenafil.

A $p<0.05$ for multiple comparison of mean values across the groups by posthoc analysis except group B and group D. wound healing and flap survival [3]. In understanding these factors, various methods have been devised to improve blood flow into flaps and to facilitate angiogenesis. Despite this, flap necrosis remains an unsolved important challenge for plastic surgeons [4].

In the management of patients undergoing flap reconstruction, modifiable factors include smoking cessation, nutrition optimization, minimal use of electrocautery, delicate handling of flap and vascular pedicles, and avoidance of pedicle twist. In addition, various pharmaceutical agents have been used to improve flap blood flow ever since such method was first reported by Adamson et al. [5]. For instance, Leite et al. [6] observed that dimethyl sulfoxide, a strong antioxidant, was useful in ameliorating the deleterious effect of nicotine on flap survival. Pentoxyfilline, a nonselective PDE inhibitor, reduces blood viscosity and improves flap survival, and anthrocyanins are found to have an anti-inflammatory action against reperfusion injuries in a rat model [7].

PGE1 has also been effective in improving flap survivability in experimental and clinical studies. Prostaglandins were first discovered by Euler, and are long chain polyunsaturated fatty acids generated from arachidonic acid through cycloxygenation. These eicosanoid complexes are classified according to the number of intra-structural double bonds. Of the various prostaglandins, prostaglandin A and prostaglandin E are known to induce vasodilation, with prostaglandin F promoting vasoconstriction.

PGE1 selectively relaxes smooth muscles of medium-sized blood vessels, independent of $\beta$-receptors of sympathetic nervous system. PGE1-induced vasodilation reduces systemic vascular resistance and enhances blood flow rate. In addition to vascular smooth muscle tone, the prostaglandin inhibits secretion of platelet aggregation factors such as thrombin, adenosine diphosphate, intravascular collagen, and serotonin. It also inhibits platelet aggregation by increasing the cyclic adenosine monophosphate (cAMP) concentration within platelets, and increases arteriole blood flow by improving the ability to transform erythrocyte membrane and by enhancing blood fluidity. It is also known to prevent oxygen free radicals from being generated and to help flaps survive surgical flap procedure by weakening neutrophil adherence competence and by reducing vascular endothelial cell injuries. While endogenous PGE1 is rapidly metabolized and inac- 
tivated in the lung, the principle active component of apostil is Lipo-PGE1, which uses micro-fat globules as carriers and has a longer half-life in the body.

Sildenafil citrate is a phospodiesterase- 5 inhibitor and prevents degradation of cyclic GMP within the nitrogen guanylate cyclase pathway, which subsequently prevents NO depletion [8]. Tsai et al. [9] demonstrated that intraperitoneal administration of $10 \mathrm{mg} /$ $\mathrm{Kg} /$ day of sildenafil citrate was effective in improving the flap survival rate in rats. In a similar study using the rat model, Sarifakioglu et al. [10] found a dose-dependent relationship between sildenafil citrate, with higher doses associated with improve flap survival.

The current study investigated whether the combination of alprostadil and sildenafil citrate was superior to either sildenafil-only or alprostadil-only treatment. Compared to the control group, administration of sildenafil, alprostadil, or a combination of both was associated with significant decreases in flap necrosis. Administration of either sildenafil alone or alprostadil alone was associated with lower NI through the postoperative week, although this difference was not statistically significant.

The pharmacological mechanism of the combined use of alprostadil and sildenafil is not clearly understood. The synergistic effect between alprostadil and sildenafil observed in this study may be due to increased blood flow from vasodilation, as well as increased neovascularization from fibroblast growth factor and vascular endothelial growth factor secretion via the phosphokinase $G$ pathway affected by sildenafil.

This study has some limitations. Photographic evaluation of necrotic areas can vary across observers. Pharmacokinetic management appeared to be associated with decreased flap necrosis, but the study may not have been adequately powered to detect statistical relationship. The flap model in rat represents random skin flap, and the result cannot be generalized to axial or free transfer flaps.

While sildenafil citrate was found to be very effective in enhancing the flap survival rate in this study, continuous administration can result in undesirable symptoms. Such side effects include headache, hot flush, nasal congestion, and dyspepsia, all of which are primarily attributed to vasodilation characterized by sildenafil citrate [11]. It can also inhibit the functions of platelet, prevent platelet aggregation, and cause gastric ulcer. In addition, it can be hazard- ous for heart disease patients since it may weaken cyclic adenosine monophosphate-specific PDE isoform-3 involved in cardiac constriction, dilate blood vessels, and decrease blood pressure abruptly [12]. It is necessary to conduct further research to determine a dose and concentration of sildenafil citrate that can maximize the flap survival rate while preventing systemic adverse effects and to identify long-term effects and complications of sildenafil administration combined with alprostadil and other agents.

In this study, sildenafil citrate and alprostadil were used in single-agent and combination prophylaxis against flap necrosis in rats. Single administration of sildenafil citrate following surgical flap procedure dilated blood vessels, increased blood flow into flaps, prevented flap necrosis, and improved the flap survival rate as much as that observed with alprostadil. The combined use of sildenafil and alprostadil was associated with lowest mean necrosis ratio, but the difference was statistically not significant from alprostadil-only management. Future research should be directed in elucidating the synergistic mechanism between the two vasodilatory agents in patients undergoing flap reconstruction and in patients with vascular disease.

\section{REFERENCES}

1. Prasetyono TO, Adianto S. The relationship between oxygen saturation and color alteration of a compromised skin flap: experimental study on the rabbit. Arch Plast Surg 2013;40:505-9.

2. Clark JM, Wang TD. Skin flaps designs [Internet]. New York: WebMD LLC; c2015 [cited 2015 Apr 1]. Available from: http://emedicine.medscape.com/article/875968-overview\#showall.

3. Lim H, Han DH, Lee IJ, Park MC. A simple strategy in avulsion flap injury: prediction of flap viability using wood's lamp illumination and resurfacing with a full-thickness skin graft. Arch Plast Surg 2014;41: 126-32.

4. Vural E, Key JM. Complications, salvage, and enhancement of local flaps in facial reconstruction. Otolaryngol Clin North Am 2001;34: 739-51.

5. Adamson JE, Horton CE, Crawford HH, Ayers W Jr. The effects of dimethyl sulfoxide on the experimental pedicle flap: a preliminary report. Plast Reconstr Surg 1966;37:105-10.

6. Leite MT, Gomes HC, Percario S, Russo CR, Ferreira LM. Dimethyl sulfoxide as a block to the deleterious effect of nicotine in a random skin flap in the rat. Plast Reconstr Surg 2007;120:1819-22.

7. Mauad RJ Jr, Shimizu MH, Mauad T, de Tolosa EM. Buflomedil and pentoxifylline in the viability of dorsal cutaneous flaps of rats treated 
with nicotine. J Plast Reconstr Aesthet Surg 2006;59:387-92.

8. Zhang R, Wang L, Zhang L, Chen J, Zhu Z, Zhang Z, et al. Nitric oxide enhances angiogenesis via the synthesis of vascular endothelial growth factor and cGMP after stroke in the rat. Circ Res 2003;92:308-13.

9. Tsai JW, Ayubi FS, Hart KL, Baur DA, Parham MA, Moon JK, et al. Evaluation of the effect of sildenafil and vascular endothelium growth factor combination treatment on skin flap survival in rats. Aesthetic Plast Surg 2008;32: 624-31.
10. Sarifakioglu N, Gokrem S, Ates L, Akbuga UB, Aslan G. The influence of sildenafil on random skin flap survival in rats: an experimental study. Br J Plast Surg 2004;57:769-72.

11. Moreira SG Jr, Brannigan RE, Spitz A, Orejuela FJ, Lipshultz LI, Kim ED. Side-effect profile of sildenafil citrate (Viagra) in clinical practice. Urology 2000;56:474-6.

12. Lim PH, Moorthy P, Benton KG. The clinical safety of viagra. Ann N Y Acad Sci 2002;962:378-88. 